\title{
Article \\ Wastewater Treatment Using Alkali-Activated-Based Sorbents Produced from Blast Furnace Slag
}

\author{
Saverio Latorrata ${ }^{1, *(\mathbb{D})}$, Riccardo Balzarotti ${ }^{1,2, *(\mathbb{D})}$, Maria Isabella Adami ${ }^{1}$, Bianca Marino ${ }^{1}\left(\mathbb{D}\right.$, Silvia Mostoni ${ }^{3}(\mathbb{D}$, \\ Roberto Scotti ${ }^{3}$, Maurizio Bellotto ${ }^{4}$ and Cinzia Cristiani ${ }^{1}$ (D) \\ 1 Department of Chemistry, Materials and Chemical Engineering "Giulio Natta”, Politecnico di Milano, \\ Piazza Leonardo da Vinci 32, 20133 Milano, Italy; maria.adami@mail.polimi.it (M.I.A.); \\ bianca.marino@polimi.it (B.M.); cinzia.cristiani@polimi.it (C.C.) \\ 2 Elettrotecnica ROLD S.r.l., Via della Merlata 1, 20014 Nerviano, Italy \\ 3 Department of Materials Science, INSTM, University of Milano-Bicocca, Via R. Cozzi 55, 20125 Milano, Italy; \\ silvia.mostoni@unimib.it (S.M.); roberto.scotti@unimib.it (R.S.) \\ 4 Opigeo S.r.l., Via Monte Cengio 28/1, 35138 Padova, Italy; maurizio.bellotto@opigeo.eu \\ * Correspondence: saverio.latorrata@polimi.it (S.L.); riccardo.balzarotti@polimi.it (R.B.)
}

Citation: Latorrata, S.; Balzarotti, R.; Adami, M.I.; Marino, B.; Mostoni, S.; Scotti, R.; Bellotto, M.; Cristiani, C. Wastewater Treatment Using Alkali-Activated-Based Sorbents Produced from Blast Furnace Slag. Appl. Sci. 2021, 11, 2985. https:// doi.org/10.3390/app11072985

Academic Editor: Francisco Alguacil

Received: 28 February 2021

Accepted: 23 March 2021

Published: 26 March 2021

Publisher's Note: MDPI stays neutral with regard to jurisdictional claims in published maps and institutional affiliations.

Copyright: (c) 2021 by the authors. Licensee MDPI, Basel, Switzerland. This article is an open access article distributed under the terms and conditions of the Creative Commons Attribution (CC BY) license (https:/ / creativecommons.org/licenses/by/ $4.0 /)$.
Featured Application: The presence of toxic metals and metalloids such as $\mathrm{Cu}, \mathrm{Ni}, \mathrm{Pb}, \mathrm{As}$, and $\mathrm{Sb}$ in water resources is a global concern. They are among the most toxic heavy metal pollutants discharged into the environment and their presence in elevated concentrations can cause acute poisoning. Presently, adsorption is one of the most used techniques to remove heavy metals from wastewaters. The development of cost effective, environmentally friendly, and sustainable sorbents is of paramount importance in the framework of the sustainability agenda. In this respect, the use of waste-based geopolymers as sorbent solids can be a very good opportunity to contribute to cleaner and sustainable processes. Waste-based geopolymers can be produced with a quite low energy input, keeping the activating solution quantities at low values, and performing the reaction synthesis at room temperature, thus mitigating the release of greenhouse gases. In addition to that, their reuse after exhaustion in other applications is possible. For example, they can be used in building applications, which is not feasible for the already-known activated carbon adsorbents that have very high production costs and very challenging recovery after use.

Abstract: Currently, slags from secondary steel production, foundries, and blast furnaces represent a major environmental problem since they end up mainly in landfills, and their valorization would bring undeniable advantages both to environment and economy. Moreover, the removal of heavy metal ions from mines wastewater is one of the challenges of the last decades, and adsorption has been proposed as one of the most promising techniques for this purpose. In this context, the use of alkali-activated slags as sorbent can be a good opportunity to develop low cost, environmentally friendly, and sustainable materials. Accordingly, wastewater decontamination by adsorption over a porous monolithic bed made of alkali-activated hydraulic binders is proposed. Alkali-activated materials were prepared using slags from the metallurgical industry and reacted with an alkaline component (high alumina calcium aluminate cement, CAC 80) at ambient conditions. The obtained monolithic foams were tested to evaluate the uptake efficiency towards metal capture. Solutions containing $\mathrm{Cu}(\mathrm{II}), \mathrm{Fe}(\mathrm{III}), \mathrm{Ni}(\mathrm{II}), \mathrm{Mn}(\mathrm{II})$, and simulating the metal concentrations of a real mine effluent were tested, both in single- and multi-ion solutions. Promising capture efficiency, values of $80-100 \%$ and of $98-100 \%$ in the case of the single ion and of the multi-ion solutions were obtained, respectively.

Keywords: alkali-activated binders; blast furnaces slags; water treatment; waste valorization

\section{Introduction}

The presence of toxic metals and metalloids in water resources is currently a global concern $[1,2]$. Past fast industrialization without policies attentive to environment preser- 
vation has seriously contributed to the release of toxic pollutants in water streams. Unlike organic wastes, heavy metals are not biodegradable, but they can be adsorbed and accumulated in the environment and living organisms, causing various disorders and health problems. In the last years, awareness has grown of the fact that emissions prevention, rather than remediation of damage, is more economic and efficient for mitigating impacts on the environment [3].

There are a number of anthropogenic contributors to heavy metals release in the aquatic environment, and uncontrolled mining operations are certainly among them. Indeed, mining wastewater can contain a large amount of heavy metal ions, such as $\mathrm{Cu}$, $\mathrm{Zn}, \mathrm{Fe}, \mathrm{Mn}, \mathrm{Ni}, \mathrm{Cr}, \mathrm{Cd}$, and $\mathrm{Pb}$, and they must be treated before water reintroduction into the environment [3-5].

Therefore, various methods for heavy metal removal from wastewater have been extensively studied and proposed [6,7]. Proposed technologies include chemical precipitation, ion-exchange, adsorption, membrane filtration, coagulation-flocculation, flotation, and electrochemical methods. However, ion-exchange, adsorption, and membrane filtration are the most frequently proposed solutions for this purpose. Adsorption, in particular, can be very effective, thanks to the wide variety of available sorbents, the high recovery efficiency, the fast extraction time, the low cost, and the low consumption of organic solvents. Common examples of sorbents are activated carbon, clay minerals, inorganic oxides, porous organic polymers, or organic-inorganic hybrid materials. In particular, our research group proposed the use of hybrid organic-inorganic mineral clays [8-10], carbon [11], and reduced graphene oxide [12] based materials both for heavy metals and rare earths capture, and demonstrated their effectiveness in metal removal, also when present at high concentration.

Moreover, considering the new circular and greener economy paradigm, the development of sorbents, not only low cost, but also environmentally friendly and sustainable, is a key point of study $[13,14]$.

Therefore, both academia and industry are putting in much effort to transform wastes or byproducts that could be used as sorbents in wastewater treatment. Such an approach will positively impact environmental preservation and the responsible use of resources, including water, fulfilling the "Sustainability Agenda" goals (namely, goals number 3, 6, 9, $12,13,14$, and 15) [15].

Among others, by-products and residual wastes of steel manufacturing have gained attention as possible sorbent starting materials, due to their composition and their large availability, which poses strong environmental issues [16].

Therefore, actions allowing the reduction of the environmental impact, such as for instance red mud and blast furnace slag valorization as potential sources of raw materials, are of course welcome [17].

In this respect, the use of waste-based geopolymers or alkali-activated materials [18] as sorbents can be a very good opportunity to contribute to a cleaner production and to mitigate the greenhouse effects of the steel-making industry. The term "geopolymer" identifies a class of ceramic-like and closely related materials, which are obtained via metakaolin activation with alkali silicate solutions. Recently, the term has been used also to refer to the most varied starting precursors, which can be a source of aluminosilicates. Alkali activation allows for the achievement of Al-O-Si bonded mineral polymers. For their production, the use of various industrial waste streams as precursors, such as for instance fly ash, granulated blast furnace slag waste materials, metallurgical slags, glass wastes, has been proposed $[19,20]$.

Alkali-activated materials synthesis can be performed with a quite low energy input, keeping the alkaline activation at low values, and performing the reaction at room temperature, mitigating the release of greenhouse gases. Moreover, they could be reused in other applications after exhaustion when used as sorbents for water depollution, e.g., as an aggregate in the production of new building materials, which is not possible for materials in use presently. 
Fly ashes have been found to be a potential and versatile sorbent material for the removal of toxic metals, like lead or copper, from aqueous solutions [21], but they show a quite low adsorption capacity if used just as raw fly ashes [22]. However, to become part of an alkali-activated geopolymer, they need to be reacted with an alkali activator, thus requiring the need for further chemical treatments [19]. Fly ashes-based by-products from coal power plants are also interesting as their high silica content makes them possible precursors of nano-porous materials with high surface area and large pore volume, which can be exploited not only in wastewater treatment but also in carbon dioxide capture. Considering the alumina-silicate nature of fly ash, it can be potentially regarded as a source of different sorbent materials, depending on its origin and chemical activation, for several industrial processes. It has also been successfully employed as a precursor of fillers for the development of mixed matrix membranes (MMMs) to separate carbon dioxide from methane [23]. Moreover, it could also be considered a suitable substitute for lime to enrich soils [24].

Recently, conversion of fly ashes into geopolymer systems has arisen as a very interesting opportunity for wastewater treatment because of their effective absorption and immobilization of heavy metals. The structure of geopolymers is very similar to that of zeolites, as it consists of a negatively charged aluminosilicate framework with chargebalancing exchangeable cations, but, unlike zeolites, geopolymers are amorphous or only partially crystalline.

Blast furnace slag (i.e., the by-product generated during pig-iron production) is another low-cost sorbent showing the ability to adsorb heavy metals. Blast furnaces generate a large volume of granular blast furnace slag that is also being used as a constituent of concrete or in the production of slag cement. Accordingly, the use of the blast furnace granulated slag as an aluminosilicate source alternative to fly ashes, to synthesize alkali-activated materials, has to be considered [13].

Moreover, from an industrial perspective, column-type continuous flow operations have obvious advantages over batch-type operations. In column operations, for instance, the sorbents are continuously in contact with a fresh solution, thus favoring adsorption. In addition to that, the regeneration and recovery steps in an in-column process is easier, which is of paramount importance in wastewater treatment processes [13].

Porous monoliths can be a viable alternative to packed columns. Monolithic sorbents, like packed-bed ones, have the advantage of continuously decontaminating liquid effluents and of being considered an ultimate waste for their good mechanical resistance and permanent fixation of the pollutants; but they can also be re-used, for instance, as raw material for building applications, without treatment [13].

In this respect, geopolymers appear to be good candidates as raw materials for the synthesis of porous monoliths. Recently, the use of alkali-activated materials properly designed to contain pores, has been reported. In this respect, much attention has been paid to geopolymeric foams, i.e., solid materials characterized by a low density structure of $3 \mathrm{D}$ network of interconnected pores. One of the most applied synthetic routes to obtain the foams implies the incorporation of a foaming agent (e.g., hydrogen peroxide) into the slurry of the alkali-activated material. The in-situ reactions of the foaming agent generate gas bubbles that are then trapped inside the aluminosilicate precursors during the alkali activation reaction. This way, a porous structure forms in the hardened body [25,26].

Despite sorption capacities of geopolymers and alkali-activated materials having been already reported [27-29], their production in porous monoliths and their use in metal capture from wastewater still need to be further investigated.

Therefore, this paper aims to demonstrate the applicability of geopolymeric monoliths, produced starting from wastes, namely blast furnace slags, as wastewater filters to reduce heavy metal ions content, and to achieve an acceptable ions concentration suitable for water reuse. Preliminary results on ions capture when treating solutions containing $\mathrm{Cu}(\mathrm{II})$, $\mathrm{Fe}(\mathrm{III}), \mathrm{Ni}(\mathrm{II}), \mathrm{Mn}(\mathrm{II})$, which simulates the metal concentrations of a real mine effluent, are 
reported. Both single- and multi-ion solutions are considered, and the porous monolithsmetal possible interaction is also analyzed to get information on the capture mechanism.

\section{Materials and Methods}

\subsection{Alkali-Activated Materials and Monoliths Preparation}

The alkali-activated monoliths (PGM, in the following) were prepared according to a recipe developed by Opigeo Srl, Padova, Italy. Blast furnace slag (aluminosilicate source) was blended with high alumina calcium aluminate cement CAC-80 and $\mathrm{Li}_{2} \mathrm{CO}_{3}$ as a setting accelerator. Blast furnace slag was obtained from Ecocem, Aix-en-Provence, France, while CAC-80 was obtained from Istra Cement DOO, Pula, Croatia. The elemental chemical composition of the blast furnace slag and of the high alumina calcium aluminate cement is reported in Table 1. The alkali-activated binder was formulated with $20 \%$ by weight of CAC- 80 and $80 \%$ by weight of blast furnace slag, and with the addition of $0.004 \%$ by weight of $\mathrm{Li}_{2} \mathrm{CO}_{3}(0.02 \%$ over CAC-80).

Table 1. Elemental composition of blast furnace slag and high alumina cement.

\begin{tabular}{ccc}
\hline Oxide Type & $\begin{array}{c}\text { Oxide Content in Blast } \\
\text { Furnace Slag }(\% \text { w/w) }\end{array}$ & $\begin{array}{c}\text { Oxide Content in Calcium } \\
\text { Aluminate Cement }(\% \text { w/w })\end{array}$ \\
\hline $\mathrm{SiO}_{2}$ & 36.23 & 0.35 \\
$\mathrm{Al}_{2} \mathrm{O}_{3}$ & 10.70 & 80.73 \\
$\mathrm{CaO}$ & 40.92 & 16.97 \\
$\mathrm{MgO}$ & 7.41 & 0.46 \\
$\mathrm{Fe}_{2} \mathrm{O}_{3}$ & 0.72 & 0.20 \\
$\mathrm{TiO}_{2}$ & 0.68 & 0.23 \\
$\mathrm{MnO}$ & 0.27 & - \\
$\mathrm{K}_{2} \mathrm{O}$ & 0.45 & 0.37 \\
$\mathrm{Na}_{2} \mathrm{O}$ & 0.22 & 0.31 \\
$\mathrm{P}_{2} \mathrm{O}_{5}$ & 0.01 & - \\
others & 2.39 & 0.38 \\
\hline
\end{tabular}

The binder was mixed with water at the water-to-solid ratio of 0.4 by weight. The mixture was foamed, to reach the desired porosity, with the addition of an aqueous solution of hydrogen peroxide (foaming agent). Hydrogen peroxide $130 \mathrm{Vol}$. was used, and the weight ratio $\mathrm{H}_{2} \mathrm{O}_{2} / \mathrm{H}_{2} \mathrm{O}$ was 0.02 . The bubbles, generated during $\mathrm{H}_{2} \mathrm{O}_{2}$ decomposition, were stabilized with the addition of two surfactants, in particular cocamidopropyl betaine (Sigma Aldrich, Milan, Italy, 99\%) and myristic acid (BASF, 30-40\%) in the ratio 85:15. Cocamidopropyl betaine was used at a concentration of $1 / 3$ its critical micellar concentration, i.e., at $0.084 \mathrm{~g} / 100 \mathrm{~mL}$, while myristic acid was used at $0.015 \mathrm{~g} / 100 \mathrm{~mL}$. The formulation of the alkali-activated sorbent is reported in Table 2.

Table 2. Formulation used in the porous monolith synthesis.

\begin{tabular}{|c|c|c|}
\hline Component & Effect & Content \\
\hline Blust Furnace Slag & Aluminosilicates source & $80 \%(w / w)$ \\
\hline Cement CAC-80 & Aluminosilicates source, weak alkali, binder & $20 \%(w / w)$ \\
\hline $\mathrm{Li}_{2} \mathrm{CO}_{3}$ & setting accelerator & $0.02 \%(w / w)$ \\
\hline $\mathrm{H}_{2} \mathrm{O}_{2}$ & Bubbles generator & $2 \%(v / v)$ \\
\hline $\mathrm{H}_{2} \mathrm{O} /$ total solids & & $0.004 \%(w / w)$ \\
\hline \multirow[t]{2}{*}{$\mathrm{H}_{2} \mathrm{O}_{2} / \mathrm{H}_{2} \mathrm{O}$} & Bubbles generator & $0.02(v / v)$ \\
\hline & & $0.0125 \mathrm{~g}$ \\
\hline \multirow[t]{3}{*}{ Cocamidopropyl betaine (COCA) } & Surfactant & $0.084 \%$ \\
\hline & & (g/100 mL liquid) \\
\hline & & $0.0022(\mathrm{~g})$ \\
\hline \multirow[t]{2}{*}{ Myristic acid (MYRAC) } & Surfactant & $0.015 \%$ \\
\hline & & (g/100 mL liquid) \\
\hline COCA/MYRAC & Surfactant, bubbles stabilizer & $15 / 85(w / w)$ \\
\hline Liquid/Solid & & 0.4 \\
\hline
\end{tabular}


In a typical experiment, the solution of the surfactants, distilled water, and hydrogen peroxide were quickly poured onto the solid components, and vigorously stirred until a dense, homogeneous, and creamy mixture was obtained. The mixing step had to be performed as quickly as possible to control the tendency to harden unevenly. In a few minutes, the $\mathrm{H}_{2} \mathrm{O}_{2}$ decomposition started, and the bubbles form. The geopolymeric monoliths are thus obtained by spreading the paste (a few minutes after the synthesis reaction) on the plane surface of a Buchner filter (Figure 1), in order to get a homogeneous layer. The Buchner is then covered with Parafilm and the monolith is let to dry overnight, and subsequently characterized by XRD, SEM-EDX, EPR, and porosity measurements. The density of the hardened porous monolith is around $1.1 \mathrm{~g} / \mathrm{mL}$.

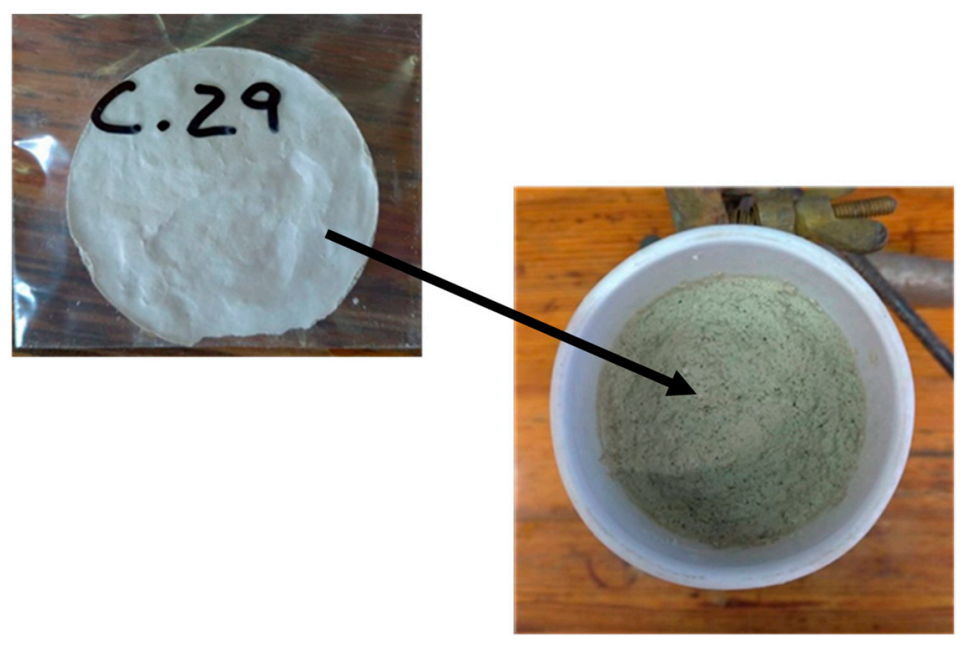

Figure 1. Example of porous monolith at the end of the process.

The X-ray diffraction (XRD) measurements were performed by Bruker D8 Advance diffractometer (Bruker Italy, Milan, Italy), using a graphite-monochromated $\mathrm{Cu} \mathrm{K} \alpha$ radiation $(\lambda=0.154 \mathrm{~nm})$, step scan $0.02^{\circ} 2 \theta$ and $1 \mathrm{~s}$ per step, in the $5-30^{\circ} 2 \theta$ range.

The scanning electron microscope-energy dispersive $X$-ray analysis (SEM-EDX) was performed with a Zeiss EVO $50 \mathrm{EP}$ (Zeiss, Jena, Germany) with a spectrometer OXFORD INCA energy 2000 (Oxford Instruments, Abingdon, UK). Samples were coated with a thin layer of gold (by an EMS K500X sputter coater, Labtech-EM, Heathfield, UK) before the analysis, in order to make surfaces conductive. The SEM was operated at EHT voltage of about $20 \mathrm{kV}$, high vacuum $(2.5 \mathrm{mPa})$, probe current of $100 \mathrm{pA}$, and working distance of $7.5 \mathrm{~mm}$.

Porosity of the material was determined by $\mathrm{Hg}$ intrusion by means of Autopore V9600 (Micromeritics Instrument Corporation, Norcross, GA, USA).

$\mathrm{Cu}(\mathrm{II})$ adsorption on porous alkali-activated monolith from monoionic copper solutions was investigated by electron paramagnetic resonance (EPR) spectroscopy, powdering the samples for the analysis. The EPR spectra were acquired by a Bruker EMX spectrometer (Bruker Italy, Milan, Italy) operating at the X-band frequency and equipped with an Oxford cryostat (Oxford Cryosystems, Long Hanborough, UK) with the following conditions: $130 \mathrm{~K}$, modulation frequency $100 \mathrm{kHz}$, modulation amplitudes $5 \mathrm{G}$, and microwave power $5 \mathrm{~mW}$. A 2,2-diphenyl-1-picrylhydrazyl (DPPH) sample was used as reference and the intensity of the spectra was normalized by sample weight, receiver gain, and filling factor of the tube.

\subsection{Mine Wastewater Model Solutions}

The obtained porous geopolymer monoliths were then used as a self-supporting filter for the treatment of waste streams, polluted with heavy metals. In particular, a synthetic aqueous solution of composition $\mathrm{Cu}(\mathrm{II}) / \mathrm{Fe}(\mathrm{III}) / \mathrm{Ni}(\mathrm{II}) / \mathrm{Mn}(\mathrm{II})=4 / 4 / 0.4 / 1(\mathrm{mg} / \mathrm{L})$ was pre- 
pared, which simulated the composition and metal concentrations in the final steps of the purification process of mine wastewater, but still containing heavy metal ions [3,4]. As ions precursors, nitrates were selected for $\left.\mathrm{Ni}^{2+}\left(\mathrm{Ni}_{(} \mathrm{NO}_{3}\right)_{2} \cdot 6 \mathrm{H}_{2} \mathrm{O}\right)$ and $\mathrm{Cu}^{2+}\left(\mathrm{Cu}\left(\mathrm{NO}_{3}\right)_{2} \cdot 6 \mathrm{H}_{2} \mathrm{O}\right)$, while chlorides were used for $\mathrm{Fe}^{3+}\left(\mathrm{FeCl}_{3} \cdot 6 \mathrm{H}_{2} \mathrm{O}\right)$ and $\mathrm{Mn}^{2+}\left(\mathrm{MnCl}_{2} \cdot 4 \mathrm{H}_{2} \mathrm{O}\right)$, all supplied by Sigma Aldrich (Sigma Aldrich Italy, Milan, Italy) (purity 98-99\%). In order to study the capture mechanism and the adsorption selectivity, the capture capacity was firstly analyzed by performing a set of experiments using the four ions in single-ion solutions, then a second set of experiments was performed on multi-ion solutions (Table 3). Single ions concentrations were selected equal to the specific ion concentration in the corresponding multi-ion solution. Measured $\mathrm{pH}$ values of the starting solutions are reported in Table 3, while those of the filtered ones were 12-12.5 for all the experiments.

Table 3. Synthetic solutions composition and EU emission limits [1,2].

\begin{tabular}{ccccc}
\hline \multirow{2}{*}{ Mono-Ionic Solution } & & & Allowed EU Limits \\
\cline { 2 - 5 } & $\mathbf{( m m o l / L )}$ & $\mathbf{( m g / L )}$ & $\mathbf{p H}$ & $\mathbf{( m g} / \mathbf{L})$ \\
\hline $\mathrm{Cu}(\mathrm{II})$ & 0.063 & 3.97 & 5.3 & 3 \\
$\mathrm{Fe}(\mathrm{III})$ & 0.072 & 4.03 & 3.8 & $1-3$ \\
$\mathrm{Ni}(\mathrm{II})$ & 0.0094 & 0.55 & 5.2 & $<0.1$ \\
$\mathrm{Mn}(\mathrm{II})$ & 0.019 & 1.05 & 5.3 & $<0.1$ \\
\hline Multi-Ion Solution & & & & \\
\hline $\mathrm{Cu}(\mathrm{II})$ & 0.063 & 3.97 & & \\
$\mathrm{Fe}(\mathrm{III})$ & 0.072 & 4.03 & 3.6 & \\
$\mathrm{Ni}(\mathrm{II})$ & 0.0094 & 0.55 & & \\
$\mathrm{Mn}(\mathrm{II})$ & 0.019 & 1.05 & & \\
\end{tabular}

Operating parameters, such as filtration time, monolith volume, and effect of the initial ion concentration were also analyzed and tuned by filtration experiments using $\mathrm{Cu}$ (II) mono-ionic solution. Monolith volumes 54.7 and $87.4 \mathrm{~cm}^{3}$ and filtration time 5, 10, and $30 \mathrm{~min}$ were studied at the fixed $\mathrm{Cu}$ initial concentration of $4 \mathrm{mg} / \mathrm{L}$; while the effect of the initial $\mathrm{Cu}$ concentration was studied for 4,8 , and $12 \mathrm{mg} / \mathrm{L}$ containing solutions at fixed volume of $54.7 \mathrm{~cm}^{3}$ and a filtration time of $10 \mathrm{~min}$.

In a typical experiment (Figure 2), $50 \mathrm{~mL}$ of the aqueous solutions were poured onto the geopolymeric monolith under vacuum (water pump) at room temperature. The vacuum pump was manually controlled, in order to fix the filtration time at 5, 10, and $30 \mathrm{~min}$.

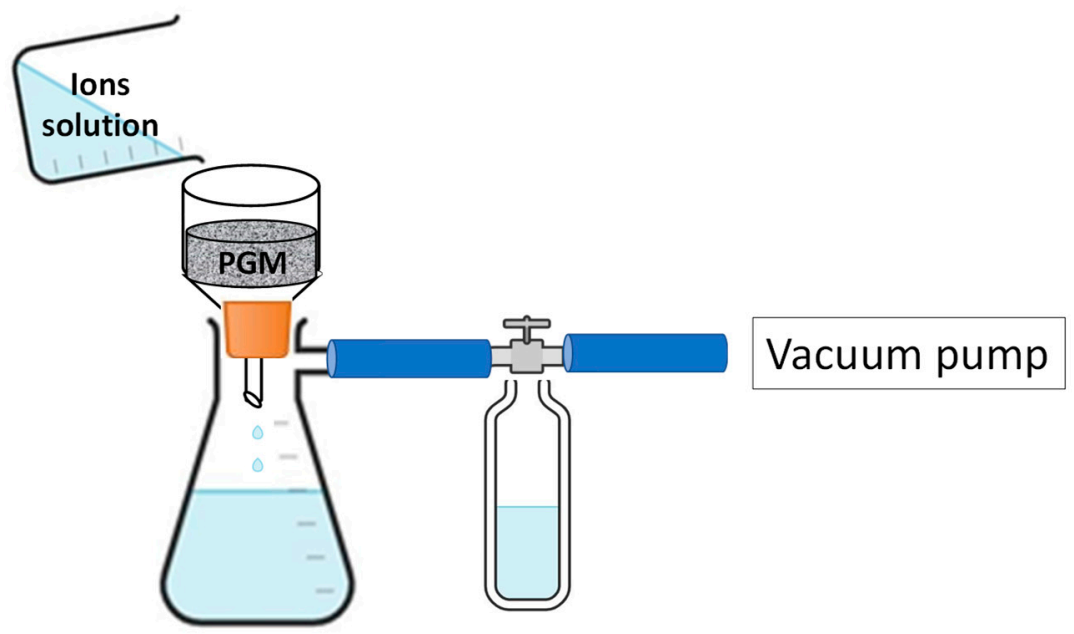

Figure 2. Filtration experimental setup. 
Metal analysis before and after the filtration step was performed by means of inductively coupled plasma - optical emission spectrometry (ICP-OES) technique using a PerkinElmer OPTIMA 7000 DV spectrometer (Perkin Elmer Italia, Milan, Italy).

The average of three measurements was considered, and the estimated error was within $1 \%$. The capture efficiency was calculated by the difference between the initial ion concentration $\left(\mathrm{C}_{0, \mathrm{i}}\right)$ in the starting solution and the residual one after filtration $\left(\mathrm{C}_{\mathrm{f}, \mathrm{i}}\right)$, according to Equation (1):

$$
\eta_{\mathrm{c}}(\%)=\frac{\mathrm{C}_{0, \mathrm{i}}-\mathrm{C}_{\mathrm{f}, \mathrm{i}}}{\mathrm{C}_{0, \mathrm{i}}} 100
$$

For all the experiments, the release of Ca ions during filtration was also controlled and measured in the range $20-300 \mathrm{mg} / \mathrm{L}$ depending on the experiment.

\section{Results}

\subsection{Porous Monoliths Characterization}

The obtained porous monoliths were characterized by XRD analysis; the pattern is reported in Figure 3.

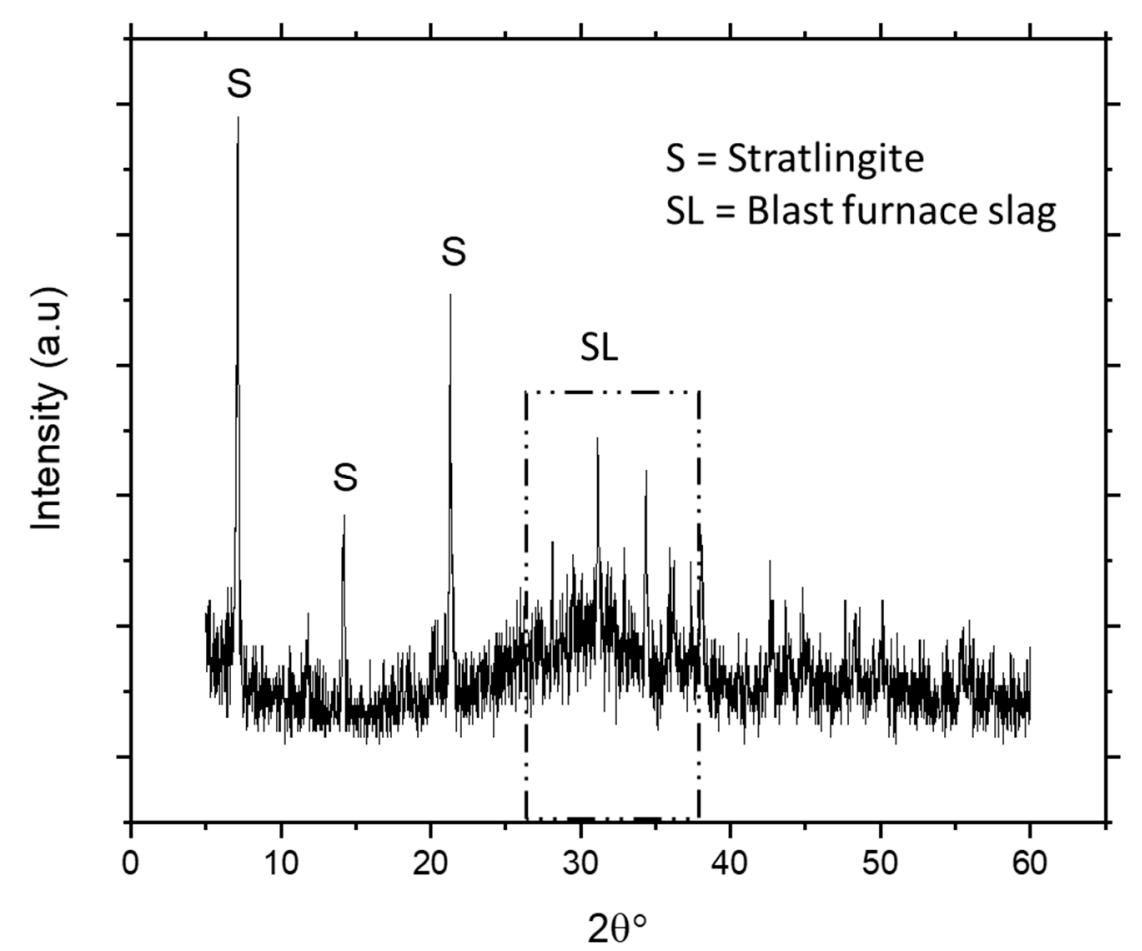

Figure 3. XRD of the alkali-activated powder (28 days of curing).

The hydration of the blast furnace slag/high alumina cement mixture after 28 days curing does not form calcium aluminate hydrates, but only stratlingite $\mathrm{Ca}_{2} \mathrm{Al}(\mathrm{AlSi}) \mathrm{O}_{2}(\mathrm{OH})_{10}$. $2.25 \mathrm{H}_{2} \mathrm{O}[30]$ is visible, along with the remnants of the amorphous halo of the blast furnace slag.

In a filtration process, i.e., the application of the synthesized monoliths, porosity is a key property for the success of the material when applied; therefore, porosity of the monoliths was determined by $\mathrm{Hg}$ intrusion (Figure 4). 


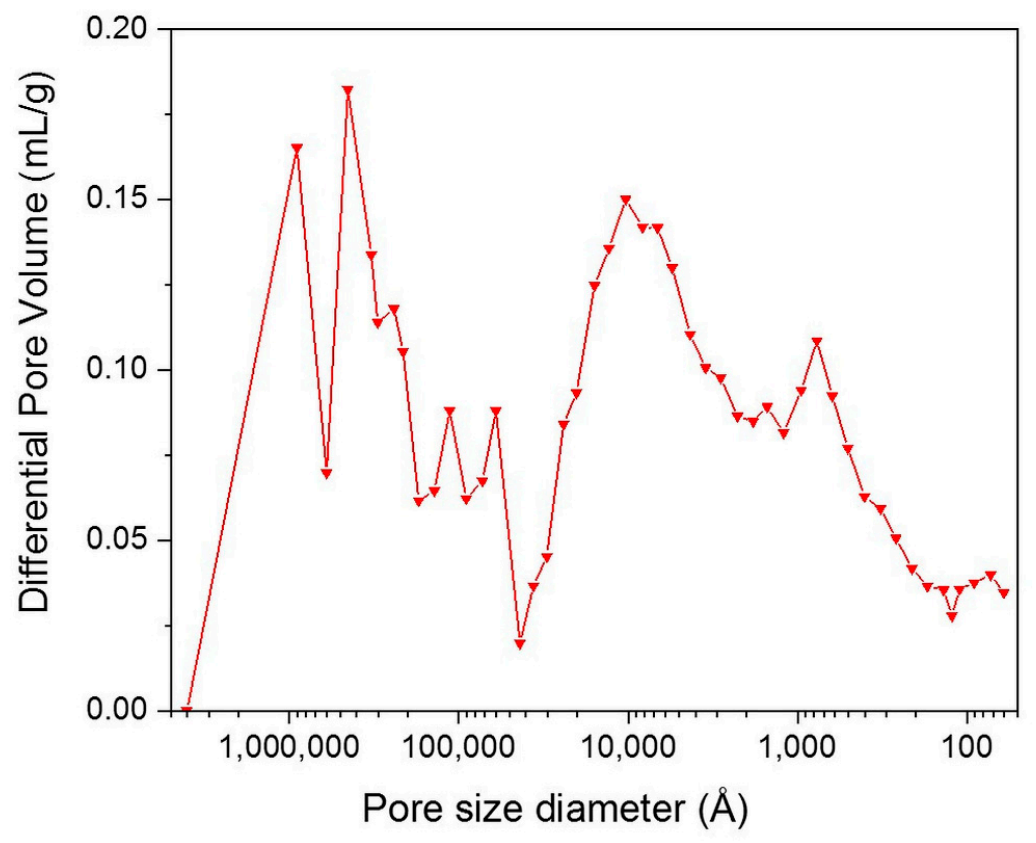

Figure 4. Pore distribution by $\mathrm{Hg}$ intrusion of the alkali-activated monolith.

A very complex pores distribution, which can be summarized in the average pore dimension of $0.14 \mu \mathrm{m}$, was found, characterized by a wider pores distribution where very large and very small pores are present (Table 4 ).

Table 4. Morphology and size of the monoliths.

\begin{tabular}{cc}
\hline Morphological Characteristics \\
\hline \\
Pore Volume $=0.46 \mathrm{~cm}^{3} / \mathrm{g}$ \\
Surface Area $=13 \mathrm{~m}^{2} / \mathrm{g}$ \\
Average Pores Diameters $=0.14 \mu \mathrm{m}$ \\
Bulk density $=1.1 \mathrm{~g} / \mathrm{mL}$ \\
Porosity $=48.7 \%$
\end{tabular}

To better evaluate and confirm the morphology and elemental composition, SEM-EDX analysis was performed on the monoliths; results on the gold-coated samples are reported in Figure 5.

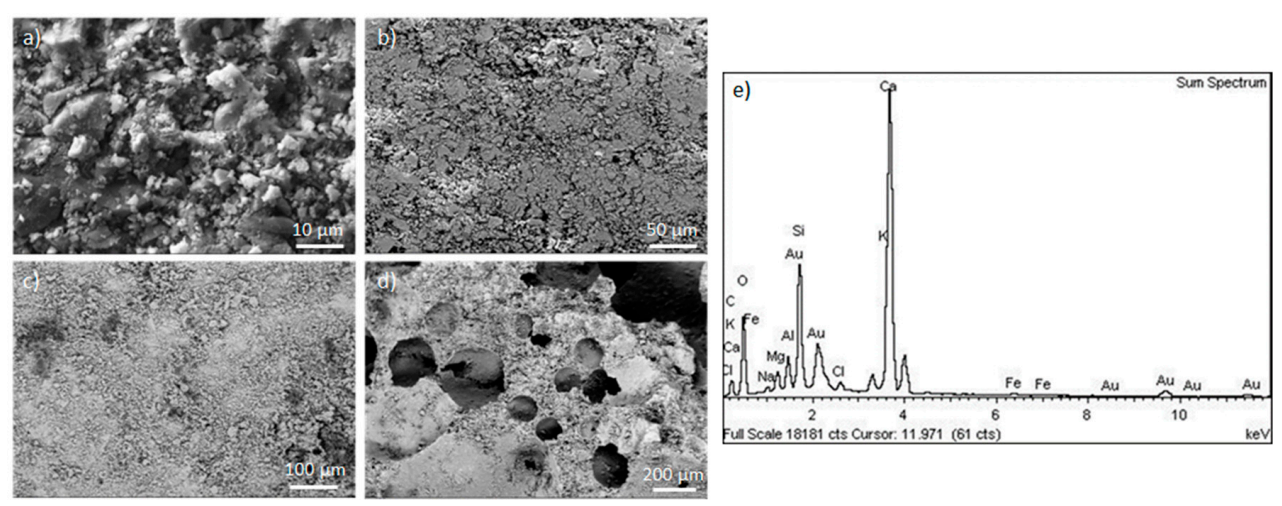

Figure 5. SEM micrographs ((a-d), at increasing enlargements) and EDX analysis of the monolith (e). 
The complex porous structure, already observed by porosity measurements, was confirmed by SEM analysis. Very large cages were accompanied by smaller pores that are homogeneously distributed in the material, thus assuring similar filtration behavior and pathways in the whole monolith volume. Moreover, the observed morphological situation was a strong indication of the direct correlation between bubbles formation during synthesis and the final material porosity. EDX experiments confirmed that the constituent powder consisted mainly of $\mathrm{Ca}, \mathrm{Si}, \mathrm{Mg}$, and $\mathrm{Al}$; small amounts of Fe ions are due to the starting slag composition.

For sake of clarity, monoliths characteristics are summarized in Table 4.

\subsection{Filtration Tests: Effect of the Operating Parameters}

To study and tune operating parameters, monoliths of different volumes (PGM1 and PGM2 in the following) were prepared, which corresponded to monoliths, containing different powder amounts (Table 4). Cu-containing solutions were used to analyze and tune the operating parameters of the filtration process; effects of the monolith volume, of the filtration time, and of the ion concentration in the initial solution were studied. All these parameters are those of choice for practical application; indeed, they could influence metal capture efficiency, results are plotted in Figure 6a-d.
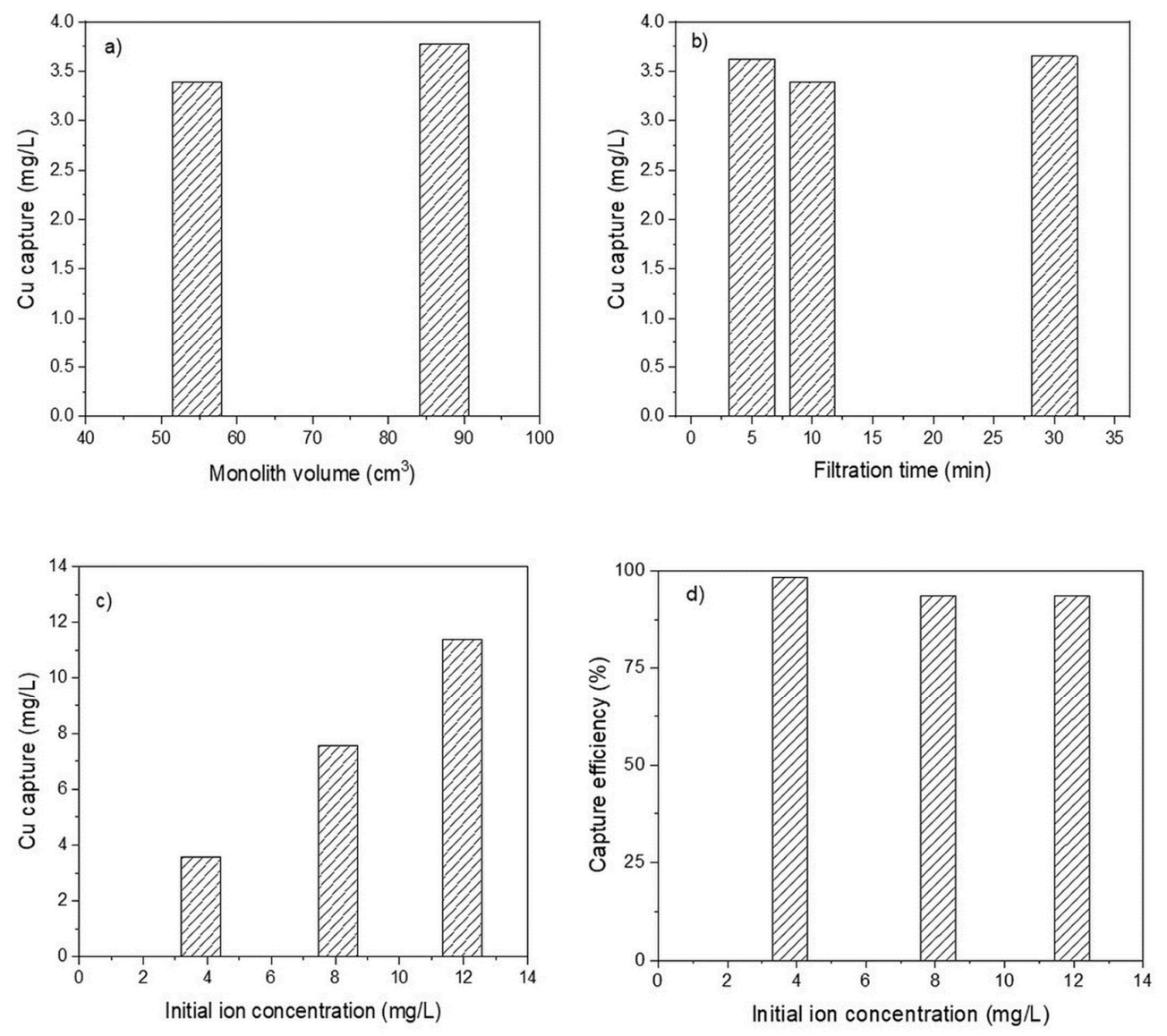

Figure 6. Effect of the operating parameters: (a) monolith volume, (b) filtration time, and (c,d) initial ion concentration.

A rather low effect of the monolith volume was observed (Figure 6a): a 30\% increase of the volume corresponded to an increase of $5 \%$ in metal capture. Considering that, at this scale, a monolith of lower volume can assure more homogeneity and reproducibility; for all the further experiments, the monolith volume was set at $54.7 \mathrm{~cm}^{3}$.

Once the monolith dimension was fixed, no remarkable effect of the filtration time was found (Figure 6b); even a six-fold increase in filtration time did not result in a higher metal 
capture, and the observed small differences were within the experimental error. Therefore, the filtration time was set at $10 \mathrm{~min}$, this time being short but better managed by a manual control of the vacuum pump.

Finally, a linear capture capability of the solids was found on increasing the initial metal concentration (Figure $6 \mathrm{c}$ ). In the explored range of metal concentrations, no saturation was found, and apparently the solid should be able to capture larger amount of ions. A very high capture efficiency was measured (Figure $6 \mathrm{~d}$ ) for $\mathrm{Cu}$ ions which laid the groundwork for the application in treating multi-ion solutions.

\subsection{Metal Capture in Mono-Ionic and Multi-Ionic Solutions}

Mono-ionic and multi-ion solutions of composition as in Table 3 were filtered on PMG1type monoliths fixing the filtration time at $10 \mathrm{~min}$. Results are reported in Figure $7 \mathrm{a}-\mathrm{c}$, where initial and captured metal ions concentrations are compared for mono-ionic and multi-ionic solutions, Figure 7a,b respectively; while capture efficiency values are plotted in Figure 7c.
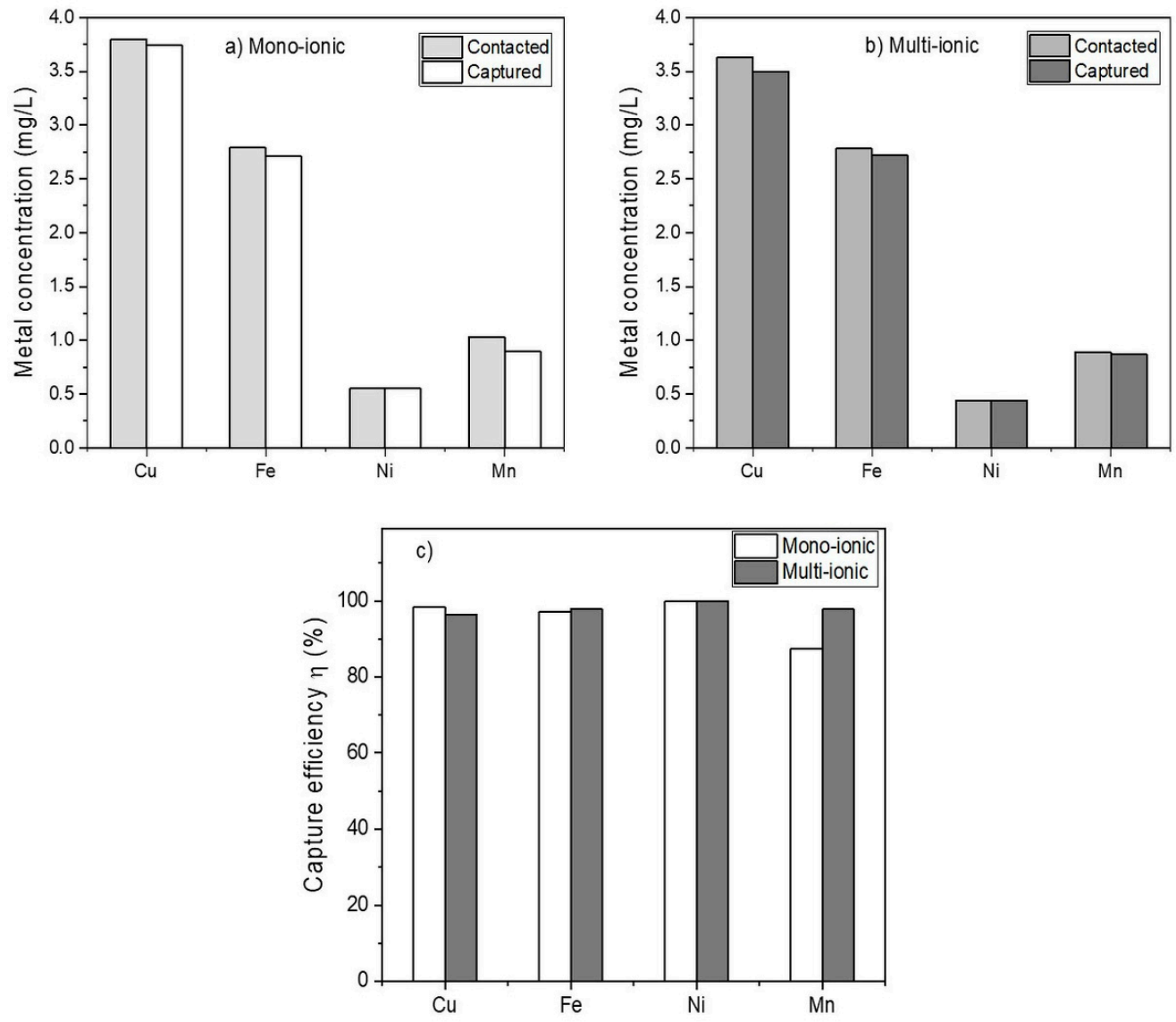

Figure 7. Results of capture tests performed on $54.7 \mathrm{~cm}^{3}$ monolith using mono-ionic (a) and multiionic (b) solutions; a comparison of capture efficiencies for both feeds is reported in (c).

According to literature data on different solution composition [31], the monolith was able to capture practically all the metal present in the initial solution; moreover, very similar capture performances were found in both mono-ionic and multi-ionic solutions. Therefore, no effect of the solution composition is apparently present, and the solid exerts its capture capability on the ions, regardless of whether they are alone or mixed in solution. The capture capability is also insensitive to the initial $\mathrm{pH}$; indeed very similar capture efficiencies, around 100\%, were observed in the case of both multi-ionic and mono-ionic solutions, whose initial $\mathrm{pH}$ was somewhat different (Table 3). On the other hand, such a high efficiency reveals a poor selectivity; indeed, the solid is not able to capture the metal ions in a differentiated way. However, the material here proposed can be efficiently applied 
to treat wastewaters in order to reach ruled EU emission limits for the heavy metal ions here considered (Table 3).

\subsection{Electron Paramagnetic Analysis of Exhausted Monoliths}

The adsorption of $\mathrm{Cu}(\mathrm{II})$ ions on the geopolymers was confirmed by EPR spectroscopy by comparing the spectra of samples before and after the adsorption of the mono-ionic $\mathrm{Cu}(\mathrm{II})$ solutions (Figure 8).

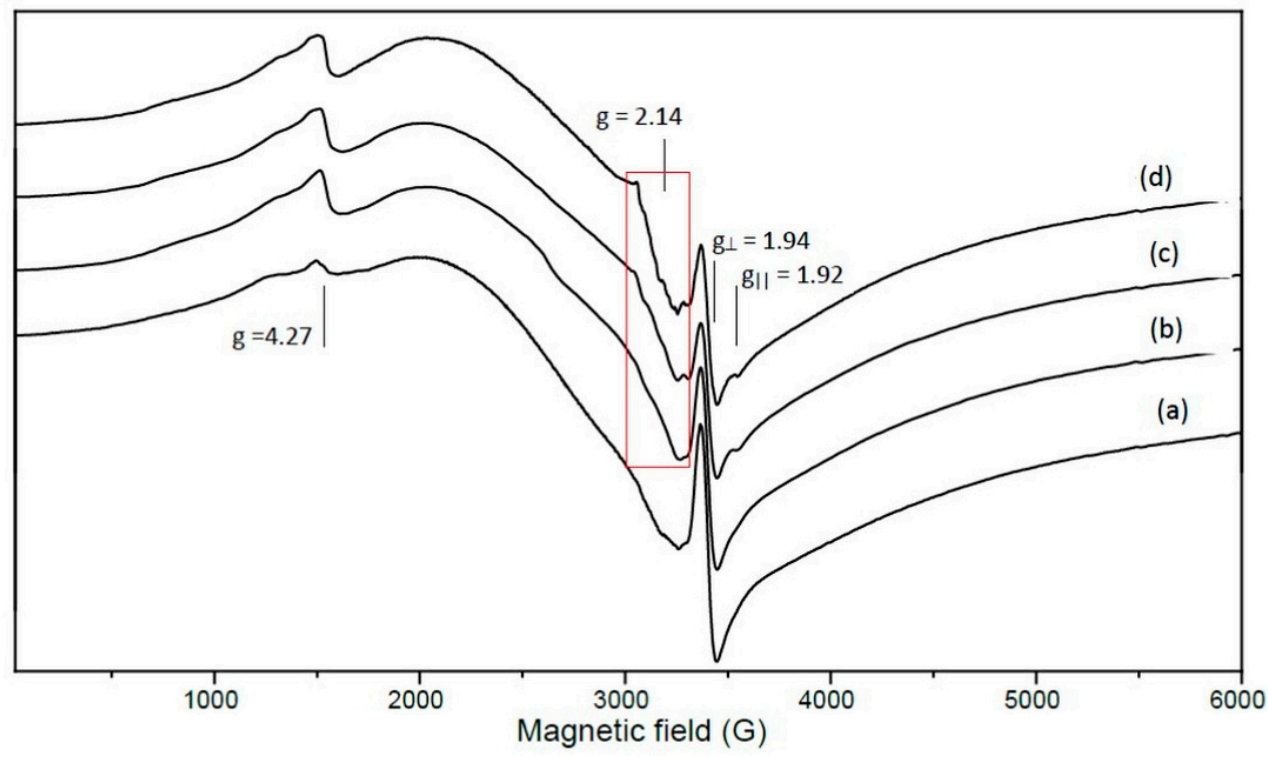

Figure 8. Electron paramagnetic resonance (EPR) spectra of monolith geopolymers before (a) and after the adsorption of mono-ionic $\mathrm{Cu}^{2+}$ solutions with concentration (b) $4 \mathrm{mg} / \mathrm{L}$; (c) $8 \mathrm{mg} / \mathrm{L}$ and (d) $12 \mathrm{mg} / \mathrm{L}$. The signals of $\mathrm{Cu}^{2+}$ are evidenced.

The spectra of geopolymers (Figure 8a) show the presence of different paramagnetic metal centers, as already observed in similar materials [32]:

i. a resonance line at $\mathrm{g}=4.3$ due to isolated $\mathrm{Fe}^{3+}$ centers located in sites with distorted octahedral symmetry;

ii. a very large and intense signal at $\mathrm{g} \approx 2.0$ (linewidth $\Delta \mathrm{H} \approx 1700 \mathrm{G}$ ), attributed to $\mathrm{Fe}^{3+}$ centers interacting by dipole-dipole in distorted octahedral or tetrahedral sites or to super-exchange coupled $\mathrm{Fe}^{3+}$ pairs [33], which may be related to the presence of a minor amount of an iron-oxygen phase;

iii. a sharp anisotropic signal at $\mathrm{g}_{\perp}=1.94$ and $\mathrm{g}_{\|}=1.92$, whose $\mathrm{g}$ values are typical of $d^{1}$ metal ions, which can be attributed to isolated $\mathrm{Ti}^{3+}$ centers $[32,34]$.

After the adsorption of the $\mathrm{Cu}(\mathrm{II})$ solutions (Figure $8 \mathrm{~b}-\mathrm{d}$ ), a new signal superimposed to that of pristine geopolymers at $g=2.14$, whose intensity increased with the concentration of the copper solution. Even if its low intensity and the superimposition with the signals of geopolymers hindered the detection of detect eventual hyperfine coupling or anisotropy of the signal and the precise identification of the symmetry of the metal ions, the signal is attributed to $\mathrm{Cu}(\mathrm{II})$ ions adsorbed on the porous geopolymers [35].

\section{Discussion}

The data shown above pose demands regarding the capture mechanism and nature of the sorbent-ion interaction. Adsorption is reported as the most probable mechanism for metal capture; however, it could be influenced by a number of factors, such as concentration, contact time, stirring rate, temperature, $\mathrm{pH}$, ionic strength, and complexity of the waste stream. Operating conditions are largely influenced not only by the sorbent nature, but also by the adsorbate. A typical example is heavy metal ions, where typical 
$\mathrm{pH}$ ranges, characteristic of each metal, correspond to no or maximum adsorption or precipitation $[13,36,37]$. It is evident that the knowledge of the behavior of the system sorbent/adsorbate is a key factor to determine operating parameters and, consequently, a successful transfer from small laboratory scale to pilot plant, and finally to larger industrial applications [38]. Different sorption mechanisms were proposed in the literature. For fly ashes, geopolymer, and faujasite, a chemisorption mechanism and a Langmuir adsorption model were proposed for $\mathrm{Pb}$ (II) [39]; while in the case of nuclear wastes treatment by geopolymer foams, a homogeneous precipitation of Cs compound on the pores wall of the foam was reported [40]. Concerning clay and organo-clay sorbents, $\mathrm{pH}$ modification and related changes in the acid-base condition and equilibria in solution were reported to be responsible for $\mathrm{Cu}$ capture in a mixed $\mathrm{Cu}$-La ions solution. Rather than to the nature of the adsorption sites, capture was found to be due to aquo- and hydroxy-copper complexes formation [36], and similar effects were also reported for reduced graphene oxide membranes [12], where solutions of composition similar to those here reported were tested.

Despite no effect on metal ions capture of the initial $\mathrm{pH}$ being detected, a certain role of the $\mathrm{pH}$ trend during the whole adsorption process has to be supposed, considering that its value at the end of the filtration ranged between 11 and 12. Such a strong basic $\mathrm{pH}$ is related to $\mathrm{Ca}$ ions release in solution during capture, which was found to range between 20 and $300 \mathrm{mg} / \mathrm{L}$, depending on the experiment. Indeed, it is well known that $\mathrm{pH}$ influences the nature of the chemical species that are present in a solution. Depending on the $\mathrm{pH}$ range, metals can be present in cationic or hydroxy form. Accordingly, $\mathrm{pH}$ variations could be considered to explain the capture mechanism. Therefore, to better understand this aspect, speciation in solution at different $\mathrm{pH}$ ranges was evaluated for the single ions. For this purpose, equilibria in solution were evaluated by Medusa software, a modeling software that, on the basis of thermodynamic data, is able to provide ranges of existence of each species as a function of $\mathrm{pH}$ [12]. A complex scenario was found, where different species were evinced from the calculation in different $\mathrm{pH}$ ranges [12]. Medusa software results are summarized in Table 5 as a function of different $\mathrm{pH}$ ranges.

Table 5. $\mathrm{pH}$ ranges and corresponding species (by MEDUSA calculation).

\begin{tabular}{cccc}
\hline Ion & $\mathbf{p H ~ 2 - 4}$ & $\mathbf{p H ~ 4 - 1 0}$ & pH 10-14 \\
\hline $\mathrm{Cu}$ & $\mathrm{Cu}^{2+}$ & $\mathrm{Cu}^{2+}, \mathrm{CuOH}^{+}, \mathrm{Cu}_{2}(\mathrm{OH})_{2}{ }^{2+}, \mathrm{CuO}$ & $\mathrm{CuO}, \mathrm{Cu}(\mathrm{OH})_{3}{ }^{-}, \mathrm{Cu}(\mathrm{OH})_{4}{ }^{2-}, \mathrm{Cu}(\mathrm{OH})_{2}$ \\
$\mathrm{Fe}$ & $\mathrm{Fe}^{3+}, \mathrm{Fe}(\mathrm{OH})_{2}{ }^{+}, \mathrm{FeOH}^{2+}$ & $\mathrm{Fe}_{2} \mathrm{O}_{3}$ & $\mathrm{Fe} \mathrm{O}_{3}, \mathrm{Fe}(\mathrm{OH})_{4}{ }^{-}$ \\
$\mathrm{Ni}$ & $\mathrm{Ni}^{2+}$ & $\mathrm{NiOH}^{+}, \mathrm{Ni}(\mathrm{OH})_{3}{ }^{-}$ & $\mathrm{Ni}(\mathrm{OH})_{2}, \mathrm{Ni}(\mathrm{OH})_{3}{ }^{-}, \mathrm{Ni}(\mathrm{OH})_{4}{ }^{2-}$ \\
$\mathrm{Mn}$ & $\mathrm{Mn}^{2+}$ & $\mathrm{Mn}^{2+}, \mathrm{MnOH}^{-}, \mathrm{Mn}_{2}(\mathrm{OH})_{3}{ }^{+}, \mathrm{Mn}(\mathrm{OH})_{2}$ & $\mathrm{Mn}(\mathrm{OH})_{2}, \mathrm{Mn}(\mathrm{OH})_{3}{ }^{-}, \mathrm{Mn}(\mathrm{OH})_{4}{ }^{2-}$ \\
\hline
\end{tabular}

In detail, for $\mathrm{pH}<4$, all the ions are present in cationic or charged complex forms, thus soluble. Similarly, for $\mathrm{pH}>10$, ions are always present in oxide or hydroxide form, thus precipitated. Some differences among the ions can be found at $\mathrm{pH}$ values between these two limit situations (i.e., 4-10). In this range, indeed, only Fe is present in a neutral form, which can be precipitated. Medusa results are also in line with literature indications on speciation and precipitation range of the selected ions [41].

By combining all this information with filtration tests results, a reasonable explanation of the geopolymers capture behavior can be attempted. In the $\mathrm{pH}$ range of the solutions after filtration (i.e., $\mathrm{pH}=12-12.5$ ), all the ions are captured by the geopolymeric filter, due to the presence of insoluble oxides and hydroxides. It can be hypothesized that ions are captured in neutral form in view of the strong basicity of the monolith surface. Indeed, ions are precipitated in their hydroxides or oxide forms by the monolith surface, and then are trapped into their pores. Such a mechanism, very efficient in terms of metal removal, could be not so effective in terms of strength of the metal-sorbent interaction. This point deserves further verification and study, being of paramount importance in case of disposal of the exhausted monoliths to landfill, to avoid release with time. 


\section{Conclusions}

Alkali-activated materials based on slags from the metallurgical industry can be formed to obtain monolithic foams to be applied in metal capture for wastewater treatment.

Monoliths have been proven able to effectively capture $\mathrm{Cu}(\mathrm{II}), \mathrm{Fe}(\mathrm{III}), \mathrm{Ni}(\mathrm{II})$, and $\mathrm{Mn}(\mathrm{II})$, in solutions simulating the metal concentrations of a real mine effluent.

Promising capture efficiency values were attained up to $80-100 \%$ and $98-100 \%$ for single ion and multi-ion solutions, respectively.

Considering filtration results and solution equilibria evaluation, metal capture appears to be related to $\mathrm{pH}$ values reached during filtration, i.e., $\mathrm{pH}=12-12.5$, which results in the presence of insoluble oxides and hydroxides in solution.

Metals are thus captured in neutral form, via precipitation induced by the monolith surface, and trapping into monolith porosity.

Such a mechanism is very efficient in terms of metal removal, but could be not so effective in terms of strengthening metal-sorbent interaction; thus, this point deserves further validation, being fundamental in the case of transfer of the exhaust monoliths to landfill or reuse for building applications.

The proposed use of waste-based geopolymers as sorbent solids is, in the authors' opinion, a very good opportunity to contribute to cleaner and sustainable processes. Their production requires quite low energy input, keeping the alkaline activation, either solid or liquid, at a low dosage, and curing the fresh mixes at room temperature, thus mitigating the release of greenhouse gases. Moreover, the possibility of reuse of the exhausted sorbent material in other applications makes them, compared to other sorbents, appealing in the present and future circular economy scenario.

Author Contributions: M.B. and C.C.: conceptualization, methodology, supervision, formal analysis, funding acquisition, writing —original draft; M.I.A. and B.M.: investigation, methodology, validation; S.M. and R.S.: investigation, validation, formal analysis, writing-review and editing; S.L.: data curation, investigation, validation, writing - review and editing; R.B.: data curation, validation, writing-review and editing. All authors have read and agreed to the published version of the manuscript.

Funding: This research received no external funding.

Institutional Review Board Statement: Not applicable.

Informed Consent Statement: Not applicable.

Data Availability Statement: The data presented in this study are available on request from the corresponding author.

Acknowledgments: Thanks are due to Opigeo (S.r.l.) Italy for providing alkali-activated materials. Giuseppina Gasti and Gigliola Clerici are acknowledged for experimental support in filtration tests and XRD.

Conflicts of Interest: The authors declare no conflict of interest.

\section{References}

1. Gautam, R.K.; Sharma, S.K.; Mahiya, S.; Chattopadhyaya, M.C. CHAPTER 1 Contamination of Heavy Metals in Aquatic Media: Transport, Toxicity and Technologies for Remediation. In Heavy Metals in Water: Presence, Removal and Safety; The Royal Society of Chemistry: London, UK, 2015; pp. 1-24. ISBN 978-1-84973-885-9.

2. World Health Organization. Guidelines for Drinking-Water Quality; World Health Organization: Geneva, Switzerland, 1993; ISBN 9789241549950.

3. Kauppila, P.; Liisa Räisänen, M.; Myllyoja, S. Best Environmental Practices in Metal Ore Mining; Finnish Environment Institute: Helsinki, Finland, 2011; ISBN 978-952-11-4188-1.

4. Northey, S.A.; Mudd, G.M.; Saarivuori, E.; Wessman-Jääskeläinen, H.; Haque, N. Water footprinting and mining: Where are the limitations and opportunities? J. Clean. Prod. 2016, 135, 1098-1116. [CrossRef]

5. Northey, S.A.; Mudd, G.M.; Werner, T.T.; Haque, N.; Yellishetty, M. Sustainable water management and improved corporate reporting in mining. Water Resour. Ind. 2019, 21, 100104. [CrossRef]

6. Fu, F.; Wang, Q. Removal of heavy metal ions from wastewaters: A review. J. Environ. Manag. 2011, 92, 407-418. [CrossRef] 
7. Gunatilake, S. Methods of Removing Heavy Metals from Industrial Wastewater. J. Multidiscip. Eng. Sci. Stud. $2015,1,14$.

8. Iannicelli-Zubiani, E.M.; Cristiani, C.; Dotelli, G.; Gallo Stampino, P.; Pelosato, R.; Mesto, E.; Schingaro, E.; Lacalamita, M. Use of natural clays as sorbent materials for rare earth ions: Materials characterization and set up of the operative parameters. Waste Manag. 2015, 46, 546-556. [CrossRef]

9. Iannicelli-Zubiani, E.M.; Cristiani, C.; Dotelli, G.; Stampino, P.G.; Bengo, I. Lanthanum uptake by clays and organo-clays: Effect of the polymer. Procedia Environ. Sci. Eng. Manag. 2014, 1, 25.

10. Iannicelli-Zubiani, E.M.; Cristiani, C.; Dotelli, G.; Stampino, P.G.; Pelosato, R.; Finocchio, E. Effect of pH in the synthesis of organo-clays for rare earths removal. Environ. Eng. Manag. J. 2017, 16, 1719-1727. [CrossRef]

11. Iannicelli-Zubiani, E.M.; Gallo Stampino, P.; Cristiani, C.; Dotelli, G. Enhanced lanthanum adsorption by amine modified activated carbon. Chem. Eng. J. 2018, 341, 75-82. [CrossRef]

12. Latorrata, S.; Cristiani, C.; Basso Peressut, A.; Brambilla, L.; Bellotto, M.; Dotelli, G.; Finocchio, E.; Gallo Stampino, P.; Ramis, G. Reduced Graphene Oxide Membranes as Potential Self-Assembling Filter for Wastewater Treatment. Minerals 2021, 11, 15. [CrossRef]

13. Ahmaruzzaman, M. Industrial wastes as low-cost potential adsorbents for the treatment of wastewater laden with heavy metals. Adv. Colloid Interface Sci. 2011, 166, 36-59. [CrossRef] [PubMed]

14. Iakovleva, E.; Sillanpää, M. The use of low-cost adsorbents for wastewater purification in mining industries. Environ. Sci. Pollut. Res. 2013, 20, 7878-7899. [CrossRef] [PubMed]

15. THE 17 GOALS I Sustainable Development. Available online: https://sdgs.un.org/goals (accessed on 24 March 2021).

16. Barella, S.; Bondi, E.; Di Cecca, C.; Ciuffini, A.F.; Gruttadauria, A.; Mapelli, C.; Mombelli, D. New perspective in steelmaking activity to increase competitiveness and reduce enviromental impact. Metall. Ital. 2014, 106, 31-39.

17. Mombelli, D.; Barella, S.; Gruttadauria, A.; Mapelli, C. Iron Recovery from Bauxite Tailings Red Mud by Thermal Reduction with Blast Furnace Sludge. Appl. Sci. 2019, 9, 4902. [CrossRef]

18. Krivenko, P. Why Alkaline Activation-60 Years of the Theory and Practice of Alkali-Activated Materials. J. Ceram. Sci. Technol. 2017, 8, 323-334. [CrossRef]

19. Davidovits, J. Synthetic Mineral Polymer Compound of the Silicoaluminates Family and Preparation Process. U.S. Patent 4,472,199, 18 September 1984.

20. Provis, J.L. Alkali-activated materials. Cem. Concr. Res. 2018, 114, 40-48. [CrossRef]

21. Luukkonen, T.; Heponiemi, A.; Runtti, H.; Pesonen, J.; Yliniemi, J.; Lassi, U. Application of alkali-activated materials for water and wastewater treatment: A review. Rev. Environ. Sci. Biotechnol. 2019, 18, 271-297. [CrossRef]

22. Davidovits, J. Geopolymer Chemistry and Applications, 5th ed.; Institut Géopolymère: Saint-Quentin, France, 2020; ISBN 9782954453118.

23. Miricioiu, M.G.; Niculescu, V.C.; Filote, C.; Raboaca, M.S.; Nechifor, G. Coal fly ash derived silica nanomaterial for mmmsapplication in $\mathrm{CO}_{2} / \mathrm{CH}_{4}$ separation. Membranes 2021, 11, 78. [CrossRef]

24. Miricioiu, M.G.; Niculescu, V.-C. Fly Ash, from Recycling to Potential Raw Material for Mesoporous Silica Synthesis. Nanomaterials 2020, 10, 474. [CrossRef]

25. Novais, R.M.; Pullar, R.C.; Labrincha, J.A. Geopolymer foams: An overview of recent advancements. Prog. Mater. Sci. 2020, 109, 100621. [CrossRef]

26. Ricciotti, L.; Occhicone, A.; Petrillo, A.; Ferone, C.; Cioffi, R.; Roviello, G. Geopolymer-based hybrid foams: Lightweight materials from a sustainable production process. J. Clean. Prod. 2020, 250, 119588. [CrossRef]

27. Novais, R.M.; Buruberri, L.H.; Seabra, M.P.; Labrincha, J.A. Novel porous fly-ash containing geopolymer monoliths for lead adsorption from wastewaters. J. Hazard. Mater. 2016, 318, 631-640. [CrossRef] [PubMed]

28. Cheng, T.W.; Lee, M.L.; Ko, M.S.; Ueng, T.H.; Yang, S.F. The heavy metal adsorption characteristics on metakaolin-based geopolymer. Appl. Clay Sci. 2012, 56, 90-96. [CrossRef]

29. Samarina, T.; Takaluoma, E. Metakaolin-Based Geopolymers for Removal of Ammonium from Municipal Wastewater. In Proceedings of the 5th World Congress on New Technologies, Lisbon, Portugal, 18-20 August 2019; pp. 195-1-195-5.

30. Ke, X.; Bernal, S.A.; Provis, J.L. Uptake of chloride and carbonate by Mg-Al and Ca-Al layered double hydroxides in simulated pore solutions of alkali-activated slag cement. Cem. Concr. Res. 2017, 100, 1-13. [CrossRef]

31. Luukkonen, T.; Runtti, H.; Niskanen, M.; Tolonen, E.-T.; Sarkkinen, M.; Kemppainen, K.; Rämö, J.; Lassi, U. Simultaneous removal of $\mathrm{Ni}(\mathrm{II}), \mathrm{As}(\mathrm{III})$, and $\mathrm{Sb}(\mathrm{III})$ from spiked mine effluent with metakaolin and blast-furnace-slag geopolymers. J. Environ. Manag. 2016, 166, 579-588. [CrossRef]

32. Le Cornec, D.; Galoisy, L.; Izoret, L.; Cormier, L.; Trcera, N.; Calas, G. Structural role of titanium on slag properties. J. Am. Ceram. Soc. 2021, 104, 105-113. [CrossRef]

33. Ardelean, I.; Păşcuţă, P.; Giurgiu, L.V. EPR and magnetic susceptibility investigations of $\mathrm{Fe}_{2} \mathrm{O}_{3}-\mathrm{B}_{2} \mathrm{O}_{3}-\mathrm{KCl}$ glasses. Int. J. Mod. Phys. B 2003, 17, 3049-3056. [CrossRef]

34. Scotti, R.; D'Arienzo, M.; Testino, A.; Morazzoni, F. Photocatalytic mineralization of phenol catalyzed by pure and mixed phase hydrothermal titanium dioxide. Appl. Catal. B Environ. 2009, 88, 497-504. [CrossRef]

35. He, H.P.; Guo, J.G.; Xie, X.D.; Peng, J.L. Location and migration of cations in $\mathrm{Cu}^{2+}$-adsorbed montmorillonite. Environ. Int. 2001, 26, 347-352. [CrossRef]

36. Cristiani, C.; Iannicelli-Zubiani, E.M.; Bellotto, M.; Dotelli, G.; Stampino, P.G.; Latorrata, S.; Ramis, G.; Finocchio, E. Capture Mechanism of La and Cu Ions in Mixed Solutions by Clay and Organoclay. Ind. Eng. Chem. Res. 2021. [CrossRef] 
37. Cristiani, C.; Iannicelli-Zubiani, E.M.; Bellotto, M.; Dotelli, G.; Finocchio, E.; Latorrata, S.; Ramis, G.; Gallo Stampino, P. Capture and release mechanism of la ions by new polyamine-based organoclays: A model system for rare-earths recovery in urban mining process. J. Environ. Chem. Eng. 2021, 9, 104730. [CrossRef]

38. Iannicelli-Zubiani, E.M.; Giani, M.I.; Recanati, F.; Dotelli, G.; Puricelli, S.; Cristiani, C. Environmental impacts of a hydrometallurgical process for electronic waste treatment: A life cycle assessment case study. J. Clean. Prod. 2017, 140, 1204-1216. [CrossRef]

39. Liu, Y.; Yan, C.; Zhang, Z.; Wang, H.; Zhou, S.; Zhou, W. A comparative study on fly ash, geopolymer and faujasite block for Pb removal from aqueous solution. Fuel 2016, 185, 181-189. [CrossRef]

40. Petlitckaia, S.; Barré, Y.; Piallat, T.; Grauby, O.; Ferry, D.; Poulesquen, A. Functionalized geopolymer foams for cesium removal from liquid nuclear waste. J. Clean. Prod. 2020, 269, 122400. [CrossRef]

41. Balintova, M.; Petrilakova, A. Study of pH Influence on Selective Precipitation of Heavy Metals from Acid Mine Drainage. Chem. Eng. Trans. 2011, 25, 345-350. [CrossRef] 